\title{
SUSTAINABILITY IN CIVIL CONSTRUCTION: APPLICATION OF AN ENVIRONMENTAL CERTIFICATION PROCESS (LEED) DURING THE CONSTRUCTION PHASE OF A HOSPITAL ENTERPRISE - RIO DE JANEIRO/BRAZIL
}

\author{
E. VAZQUEZ ${ }^{1}$, S. ROLA ${ }^{2}$, D. MARTINS ${ }^{1}$, L. ALVES ${ }^{1}$, M. FREITAS ${ }^{3} \&$ L. PINGUELLI ROSA ${ }^{3}$ \\ ${ }^{1}$ Department of Civil Construction, Federal University of Rio de Janeiro, UFRJ, Brazil. \\ ${ }^{2}$ Department of Architecture and Urbanism, Federal Rural University of Rio de Janeiro, UFRRJ, Brazil. \\ ${ }^{3}$ Post-Graduation Program on the Energy Planning, Federal University of Rio de Janeiro, COPPE/UFRJ, Brazil.
}

\begin{abstract}
World history tells us that construction has always existed to meet the immediate and basic needs of man, and, in this time of rapid growth, did not take into consideration construction techniques and environmental preservation. This paper aims to present investigation and diagnosis at the stage of site construction, exploring the environmental impacts caused by construction site, with exposure of some interventions to minimize this effect, integrating the concepts of sustainable construction. Given the historical background of continued environmental degradation caused by human needs, which resulted in serious risks to society, and knowing that more than $60 \%$ of solid wastes generated in urban centers are from the construction site, the need arises to develop techniques and solutions to mitigate these impacts. Structure of the research/approaches: The paper is structured in four parts: description of an evolutionary history regarding environmental concern, a sustainable construction issue approach, surveying interference at the stage of site construction, and a case study focusing on environmental sustainability during the site construction phase of an enterprise. Contributions: The characteristics of a sustainable building interfere directly in the relation between man/environment with issues that can be minimized when designing a project, which should be applied from the construction of a building to the end of its life cycle. A sustainable enterprise is not defined not only by environmental and social benefits in its use and operation but also in its construction.

Keywords: Construction, construction site, environment., management, sustainability.
\end{abstract}

\section{INTRODUCTION}

The Human being, when nomadic, hunted and sought only what was necessary to survive, and nature served as refuge, support, and protection. As humans began to settle in a fixed territory and grow their own food, they felt the need to create a roof to protect from the weather.

The nomadic societies sharing caves with the other animals did not interfere much on the ecosystem. Houses were built according to basic needs, and should meet the main premises: be warm in winter, cool in summer and dry when rained, and for that, in the construction of houses, the natural resources that surrounded were taken into consideration: sun, wind and soil. This kind of architecture is named 'Vernacular Architecture', since it presents local or regional characteristics [1].

Many examples can be cited throughout the history of how each population built using the elements they had around their occupations. The houses known as pau-a-pique (cob wall) show an example, because of the use of a technique in which the walls are armed with wood or bamboo and filled with clay and fiber, found in the surrounding region. Mesa Verde National Park, Colorado, United States, is a large concentration of homes located under a cliff, built between the 6th and 11th centuries with regional materials [2]. Igloos are also a very interesting way to demonstrate the use of means for shelter. Even with extreme conditions of low temperature, the shelter under ice shows to be extremely effective. 
After the Industrial Revolution (mid-20th century), which was marked by the exploitation of coal, steel, iron, and the advent of the steam engine, the crisis of development and unbalanced population growth caused suffering. The technology imposition by the dominant sectors resulted in the creation of new consumer needs and local housing.

Thus, the capacity of humans to exploit natural resources took a predatory nature, overcoming their basic needs of eating, dressing, living, and protecting them. This phase was responsible for introducing new relations of production and forms of appropriation of space, culminating in the acceleration of urbanization. The built environment in urban areas began to receive increasingly larger population groups.

Today cities exert an increasing attraction on people worldwide. In the 21 st century, the number of people living in cities continues to increase [3], as can be seen in Table 1.

Cities have to find out how to reduce the risks inherent in the tendency of contemporary urban societies to fall back on their heritage and roots as they face up to an identity crisis. In this respect, innovation in urban space design represents an opportunity to construct country's identity of places. [5].

\section{METHODOLOGY}

This work intends to present a case study on the issue of sustainability applied to the construction site of a hospital enterprise in the city of Rio de Janeiro, Brazil. It is intended to show some impacts and mitigations that the environment may suffer during the phase of construction of a building.

This paper aims to present strategies for achieving a sustainable construction site, based on the requirements of LEED (environmental certification) and the main risks and challenges to be overcome during the construction to achieve this goal. By implementing a case study, possible solutions to mitigate the risks involved are pointed out, which can be used as a tool for other construction sites.

The preparation of the paper was based on the literature review, interviews with professionals, published articles, generating proposals for efficient solutions to a sustainable construction site. The topic was developed through an exploratory field study of environmental impacts caused by the construction site with the exposure of some interventions to minimize this effect, integrating the concepts of sustainable construction.

Table 1: Percentage of population in urban areas [4].

\begin{tabular}{lllll}
\hline Years & 1950 & 1975 & 2000 & 2030 \\
\hline World total (\%) & 29.8 & 37.9 & 47.2 & 60.2 \\
Highly developed regions (\%) & 54.9 & 70.0 & 75.4 & 82.6 \\
Developing regions (\%) & 17.8 & 26.8 & 40.4 & 56.4 \\
North America (\%) & 63.9 & 73.8 & 77.4 & 84.5 \\
Latin America and Caribbean (\%) & 41.9 & 61.4 & 75.4 & 84.0 \\
Oceania (\%) & 61.6 & 72.2 & 74.1 & 77.3 \\
Europe (\%) & 52.4 & 67.3 & 73.4 & 80.5 \\
Asia (\%) & 17.4 & 24.7 & 37.5 & 54.1 \\
Africa (\%) & 14.7 & 25.2 & 37.2 & 52.9 \\
World total (million inhabitants) & 2520 & 4070 & 6060 & 8270 \\
\hline
\end{tabular}


The motivation of the work exploring the environmental impacts caused by construction site with the exposure of some interventions to minimize this effect, integrating the concepts of sustainable construction, arose after a practical experience, generating a comparison of effective solutions to a sustainable construction site.

\section{HISTORICAL EVOLUTION OF ENVIRONMENTAL CONCERN}

Given the historical background of continued environmental degradation caused by human needs, for example settling in a territory and the ambition to grow and expand, some meetings took place to discuss the topic. Until then the consequences of human action caused to the environment had not been evaluated. Debates about the risks of environmental degradation and proposed solutions to alleviate the problem began in the 1960s. The topic gained a certain importance in the years that followed, enabling some international meetings.

\subsection{Milestones in the evolution of environmental concern}

In 1945, in the United States, the American Rachel Carson proposed an article for a national magazine about the damage caused by the use of DDT (Dichloro-Diphenyl-Trichloroethane (DDT), pesticide that was widely used after World War II to combat mosquitoes responsible for malaria. In 1958, before the great slaughter of birds in Cape Cod, located at the eastern part of MassassuchetsUSA, Carson took the initiative to publish again in a magazine the dangers of spraying with DDT. In 1962, a book was published. The subject had a great impact in the United States and resulted in pressure for new environmental laws on parliamentary [6].

In 1972, the United Nations Conference on the Human Environment took place in Stockholm with the objectives of educating the countries about the importance of promoting clean air in large urban centers, cleaning of rivers in the most populated river basins, and marine pollution. That same year, the United Nations Environment Program (UNEP) was created, responsible for promoting environmental conservation and the efficient use of resources in the context of development. This Conference was the first major international meeting, with representatives of several nations, to discuss the environmental problems [7].

Since 1980, the United Nations (UN) took up the discussion of environmental issues. Indicated by the entity, the prime minister of Norway, GroHarlem Brundtland chaired the World Commission on Environment and Development to study the issue. The final document of these studies was called 'Our Common Future' (or the Brundtland Report) and was presented in April 1987 [8].

Following the publication of the report 'Our Common Future', the UN General Assembly convened the UN Conference on Environment and Development held in Rio de Janeiro in 1992. The Conference also came to be known as the Earth Summit, Rio Conference or simply Rio-92. The member countries present at the Rio de Janeiro agreed to guide their economic, social and environmental development based on the concept of sustainable development [9].

In 1997, in Kyoto, Japan, an international agreement was approved which stipulated that developed countries should reduce greenhouse gases. The Kyoto Protocol was opened for signature on December 11, 1997. After Russia ratified it in November 2004, the Protocol was established on February 16, 2005. Today it is ratified by 184 countries [10].

In 2000, CSD (Commission on Sustainable Development (CSD) of the UN suggested holding a new world summit, this time on Sustainable Development. The conference was known as Rio +10 , since it took place 10 years after the Earth Summit in 1992 in Rio de Janeiro [9].

In December 2009, an international meeting was held in Copenhagen, Denmark. Since the Kyoto Protocol will expire in 2013, it became necessary to schedule a conference to prepare an agreement 
to replace the protocol. In this conference, more defined goals for cutting emissions of greenhouse gases for both countries to industrialized and developing countries were expected. The Copenhagen negotiations ended up rather more political and economical than environmental. China and the United States, two of the biggest overall polluters, became important factors in the negotiations. Progress could also be noticed in the establishment of a fund to help developing countries to face the challenge of climate change.

\section{SUSTAINABILITY IN CIVIL CONSTRUCTION}

The urban phenomenon is continuously increasing, extending the boundaries of the city or metropolitan area. The reality in the big cities presents a number of problems that are worth mentioning. The invasion of suburban spaces causes the loss of land, natural resources, and landscape. [3].

The need to develop technologies and solutions to mitigate these impacts arises, given the increased degradation of the environment in the cities, resulting in serious risks to society, and knowing that more than $60 \%$ of solid waste generated in urban centers comes from the construction site [11].

The construction industry has been demanding qualification and improved techniques to construct more comfortable buildings and cause the minimum environmental impact. Thus, buildings designed with social responsibility are constructed.

Sustainable buildings have been the subject of many issues discussed nowadays. Sustainability and its application to buildings require a holistic view where there are many intervening aspects to be considered in a systemic and interdisciplinary way, justified by its complexity and involving multiple looks that interact with each other. Therefore, with each new project comes the need to seek solutions associated with the rational management of energy, water, solid, liquid, and gaseous waste, seeking to identify the trajectory of each resource, from the cradle to the grave, that is, from the source from which it is extracted to its final destination, and the impacts that may potentially be caused in this path, and then seek options to minimize them. Besides protecting the environment, benefits to human beings, by improving the quality of life, is expected to be pursued with all these measures [12].

These buildings must be designed and planned from several assumptions. The choice being the following: environmentally friendly materials, with low $\mathrm{CO}_{2}$ emissions; materials that generate less waste during the construction phase; compliance of the required standards, especially the ones regarding performance; suppress smaller areas of vegetation; require less energy and water in all the construction phases (construction and use).

According to Credídio [11], there are many advantages of being a sustainable enterprise. The occupants of certified green buildings have an additional productivity of 2 to $16 \%$, divided as follows: $7 \%$ due to proper lighting, $3 \%$ due to individual temperature control, $2 \%$ for the control of ventilation, $1 \%$ due to the thermal management, and $15 \%$ less absenteeism, a term used to designate the absence or delay of workers due to some intervening cause.

To effectively achieve a reduction in social and environmental negative impacts throughout the life cycle of buildings, the importance of a broad view of the enterprise should be emphasized. The whole life cycle and all aspects surrounding it should be taken into consideration, from conception to consumption.

Despite the presence of all aspects of sustainability at each stage of the life cycle of the project, the actions to be undertaken in each one of them and their potential impact vary significantly. In the enterprise, the phases of design and planning have the lowest costs and the greater possibilities of intervention, including the focus on sustainability. It is in the construction phase that everything specified must be strictly met. Projects that enhance sustainability have the potential to sell more and 
gain value in the market, pointing to a recovery of $14 \%$ of the price of the property due to an investment of 5 to $8 \%$ [13].

There are some certification processes that are already being applied worldwide, and some are in the process of implementation in Brazil. The acronyms of each one, in general, convey the goals sought. All of them have a common goal: to combine architecture and technology tools to design and build without causing damage to nature, the occupants of the building or the neighborhood. Among these labels, the ones most used are described in Table 2.

This paper aims to present the application of the LEED certification process during the construction phase of an enterprise. The phase of site construction is crucial for environmental preservation. A sustainable enterprise is defined not only by social and environmental benefits in its use, but also in its construction. This phase can cause serious damage and impacts to the neighborhood and the environment, such as the exhaustion caused by the excessive consumption or waste of natural resources and the increasing pollution caused by a poor management of the construction site.

LEED is a certification system applied by the USGBC (United States Green Building Council (USGBC), a nonprofit organization, which aims to promote environmental sustainability of buildings. The aspects evaluated by LEED refer to the environmental impact caused as a result of the processes related to the building (design, construction, and operation). LEED is composed of five evaluation criteria, as described in Table 3. In addition to the five criteria, there is a bonus item for Innovation Project, which scores some innovation that has been undertaken in the project [14].

Table 2: Certifications for Green Buildings [13].

\begin{tabular}{ll}
\hline GBTOOL & $\begin{array}{l}\text { Green Building GBToll - International Initiative for Sustainable Built } \\
\text { Environment (IISBE) }\end{array}$ \\
CASBEE & Comprehensive Assessment System for Built Environment Efficiency - Japan \\
HQE & Haute Qualité Environnementale - France \\
BREEM & BRE Environmental Assessment Method - England \\
AQUA & Alta Qualidade Ambiental - Brazil/ France \\
LEED & Leadership in Energy and Environmental Design - United States \\
\hline
\end{tabular}

Table 3: Description of criteria for LEED evaluation [14].

\begin{tabular}{ll}
\hline Sustainable Sites - SS & $\begin{array}{l}\text { Size, geographical location, and other effects of } \\
\text { building on its surroundings } \\
\text { Intelligent use of indoor and outdoor water } \\
\text { Water Efficiency - WE }\end{array}$ \\
$\begin{array}{l}\text { Installation, monitoring, and control of heating and } \\
\text { cooling systems, lighting and other equipment besides } \\
\text { the use of renewable energy } \\
\text { Environmental strategies for the use of local materials, } \\
\text { renewable and recyclable, reducing consumption and } \\
\text { encouraging reuse } \\
\text { Reduction of gases and volatile organic compounds } \\
\text { indoors, and the incorporation of sunlight and fresh air } \\
\text { Exemplary performance in any of the above categories } \\
\text { or some innovative and effective technique }\end{array}$ \\
\hline
\end{tabular}


For an enterprise to be eligible for LEED certification, it must meet the Minimum Program Requirements, which are the minimum requirements that a project must have in order to enter the certification process. The allocation of points between credits is based on the potential environmental and human benefits of each regarding a set of impact categories [14].

\section{INTERFERENCE IN THE CONSTRUCTION SITE STAGE}

It is important to try to reduce impacts or changes in the environment caused by the construction phase. These impacts result from activities during the execution of different services. The activities bring, as consequence, elements that can interact with the environment, on which the project team can interfere. To do so, it is necessary to know what environmental and social impacts that each stage of construction can create and their probability of occurrence, to make a selection of the action steps and priorities.

Many companies do not dedicate attention to the interferences caused by construction sites, which also brings significant impacts to the neighborhood (noise, visual, etc.), pollution (soil, water and air), local impacts (ecosystems, erosion, silting, transit, etc.), and consumption of resources (especially water and energy) [15].

Another major impact is the generation of waste. It is extremely important to observe and treat waste generated on construction sites, both by the quantity and the impacts caused, especially when they are taken to inadequate places. In Brazil, where $90 \%$ of the waste generated by constructions are capable of recycling, and bearing in mind their continuous generation, recycling of this waste has fundamental importance in environmental and financial criteria, in that matter the waste returns to the construction site to replace new raw materials that would be extracted from the environment. Therefore, they are treated by a federal standard, the \# 307/2002 of CONAMA - National Council of Environment (2002), which provides for their management [16].

\subsection{Probable risks in the stage of construction}

By defining the standard of the building to be built, a program for the respective needs is raised and from the scope definition it is possible to identify the likely risks and their impacts. With the identification of risks, it is possible to establish an alternative plan of action aimed at mitigation, seeking interventions to increase their environmental performance without generating high costs at the implementation stage.

\subsubsection{Removal of buildings}

In Brazil, where most buildings are reinforced concrete structures and fencing are components coated with mortar, the removal of buildings generates a large volume of waste, which results in an increased volume of landfills and the use of a large number of trucks to transport, hindering traffic in the neighborhood. Another difficulty is the equipment used for demolition which, by accident, can cause damage to the surrounding properties. Inadequate management of the removal process can lead to the carrying of the material by rain, for example, increasing the amount of solids in surface waters of the region in which it gets deposited.

\subsubsection{Removal of vegetation and erosion}

In addition to changing the landscape quality, the removal of vegetation creates a dynamic process of change in the local ecosystem, bringing risks to the fauna and flora. Another consequence of the removal of vegetation is the removal of topsoil and the exposure of the ground layer below that, in 
general, are more susceptible to erosion. The process of erosion, on a smaller scale, may stain the surrounding streets with soil, but, on a larger scale, can cause landslides, accidents, etc.

The risks of landslides should also be considered. Landslides may be caused during the excavations and foundations, and besides the risk of accidents to workers (e.g. burial), there is a risk to nearby buildings, which may have consequences as differential settlement, damage to foundations, etc., with material implications.

\subsubsection{Temporary constructions}

Besides the impact on the landscape caused to the community, temporary buildings can bring health risks, due to bad hygiene, and safety risks for the workers, due to possible accidents. The surfaces that are impermeable, shed and parking lots, for example, can cause alteration of flow regimes, due to the reduction of water infiltration into soil. With the increased runoff, among other consequences, there is an increase of the request of drainage and flooding of local roads and land.

\subsubsection{Risk of spark generation in places containing dispersed gas}

As a result of activities at construction sites, there may be unexpected leaks of gases originating from perforated pipes during demolition and excavation, or even release of gases from underground, as in the excavation of caissons. On the other hand, spark generation by an equipment or machinery as, for example, circular saws, is common among construction site activities.

\subsubsection{Storage and handling of materials}

The improper storage and handling of materials, particularly the dangerous ones, can cause chemical contamination of soil in case of leaks; deterioration of air quality by issuing, for example, volatile organic compounds (VOCs); groundwater pollution, in the case percolation of substances in the soil; changes in surface water quality, by carrying dangerous substances by the water; and alterations in health conditions of workers. Runoff can also carry improperly stored materials, such as aggregates, causing increased amounts of solids present in water bodies.

\subsubsection{Circulation and maintenance of equipment}

The circulation of materials, equipment, machinery, and vehicles, can cause various impacts, among them: the deterioration of air quality by the emission of gases or particulate matter;, noise pollution, caused by the magnitude of the generated noise;, interference in the local fauna, especially the case in rural areas, where the noise interferes with the ecosystem; nuisance to the community, both the excess noise and vehicles roaming the streets, etc.;, and changes in security conditions in the neighborhood, or even damage to built property.

Maintenance and cleaning tools, equipment, machinery, and vehicles, if made on permeable soil, can cause chemical contamination and alter the quality of the groundwater, for example, by oil spill or cleaning products. The lack of maintenance, on the other hand, can cause deterioration of air quality due to excessive emission of pollutants, noise pollution, which can also affect the local fauna, fuel or oil leaks, alteration of the safety condition for workers and the community (because of injury) and damage to built property.

\subsubsection{Consumption and waste of resources}

The consumption of natural resources in excess implies the acceleration of the exhaustion of mineral deposits and natural resources. Specifically, the use of trees in unmanaged areas generates a chain of environmental impacts, amending the fauna, flora, air, etc. The unnecessary use of water 
contributes to the scarcity of this resource, which is becoming increasingly rare, increasing demand in the region. The unnecessary use of electricity is particularly difficult during peak hours at the end of the day.

\subsubsection{Waste generation}

The generation of waste at a construction site is inevitable; however, according to CONAMA Resolution 307/2002, the priority must be not to generate waste and, secondarily, to reduce, reuse, recycle, and disposal. Losses by debris, besides representing a high cost to the builder also impact the environment twice: increasing consumption of products and increasing the volumes sent to destination areas, such as landfills, and in the case of illegal discharges, areas not suitable, such as vacant lots, streams, hills, etc.

\subsubsection{Air quality}

The air inside the buildings under construction should not present health risks to employees. The lack of fresh air directly impacts the health of the worker who works inside the building, causing discomfort, damage to health, drowsiness, loss of responsiveness, asphyxia, or death.

Excessive moisture in indoor environments is also very harmful, especially when considering the dining and living areas that often are located in basements and are susceptible to heat and humidity that can cause respiratory and other health problems due to, for example, the development of fungi. To maintain good indoor air quality, it is necessary to worry about two factors: the restrictions on the pollution issue at its source and good ventilation.

\subsubsection{Damage to third parties}

The vibration emission by machines and equipment used by workers, especially if combined with noise, can cause various health problems, such as hearing impairment. Otherwise, in the case of the neighborhood, the vibrations can cause psychological stress and health problems. In buildings, the pathologies observed are due to structural damage, which are the damages that affect the bearing capacity of the structure (such as cracks in slabs, beams or pillars and changing conditions of the foundations), and non-structural damage, which may occur as a result of structural damage (such as reflective cracking) or due to the effect of vibration in the layers of coating and sealing (such as cracks in plaster ceilings and floors).

The occupations of public roads, both by buckets placed along the curb of the premises or advancement of the construction site on the road create nuisance to the community and can cause accidents, mainly by the affect in traffic on local roads, which requires vehicles to deviate from buckets, besides reducing the sites for on-street parking.

The release of fragments, such as blocks, chips, concrete, ceramic tile, wood, etc., cause risks to workers and the neighborhood. To minimize the risk of accidents, some actions must be taken into consideration, such as the use protective individual and collective equipment. Fragments of larger size can also cause damage to the built property.

\section{CASE STUDY: SUSTAINABLE CONSTRUCTION SITE}

The case study manages the interventions that were made in the implementation of the construction site of a hospital complex in order to obtain a construction site with less environmental impact. The project has, in its scope, premises of sustainability. Strategies were established during the construction planning to meet the pre-established requirements of the LEED criteria.

The hospital is located at Avenida Ayrton Senna, in Barra da Tijuca (Fig. 8), and is composed of two blocks, one with five floors and the other with four floors. 
This project aims to achieve certification by the LEED v.2.1 process, in the categories New Construction (NC) and Health Care (HC).

This study describes the environmental impacts at the construction site and the strategies employed in order to mitigate, according to the concepts of sustainability required by LEED [14]: sustainability of space, energy efficiency, rationalization of water use, sustainability of materials and indoor environmental quality at the construction site.

\subsection{Description of the sustainability parameters}

Regarding the sustainability requirements established for the construction site, items, such as erosion control and sedimentation, reduced water consumption, treatment of solid waste generated during construction, indoor air quality, use of recycled materials, certificated materials and materials with low toxicity, are presented. The items used at this stage add points to the items used in the business end as well, accumulating points and contributing to a higher level of certification.

\subsubsection{Sustainable space}

Regarding the first item, Table 4 demonstrates the main impacts caused by the construction site and the intervention performed.

This item provides the establishment of a Plan for Control of Erosion and Sedimentation. The building has a basement, and due to the size of the building site, an excavation with the creation of embankments around the whole construction was defined. To prevent soil erosion, and the carrying of soil during heavy rains, plastic screens were adopted, for protection, as can be seen in Fig. 1 [14].

Table 4: Impacts and interventions at the construction site [15].

\begin{tabular}{lll}
\hline Sustainable space $(\mathrm{SS})$ & \multicolumn{1}{c}{ Impacts } & \multicolumn{1}{c}{ Intervention } \\
\hline & Erosion and Sedimentation & $\begin{array}{l}\text { Protected slopes and reduced } \\
\text { sediments in the air }\end{array}$ \\
\hline
\end{tabular}

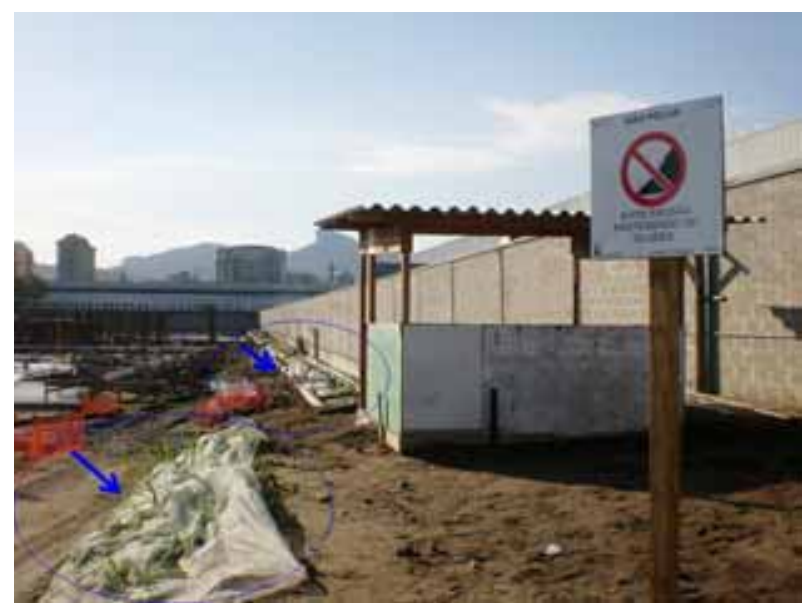

Figure 1: Embankments protected to avoid erosion. 


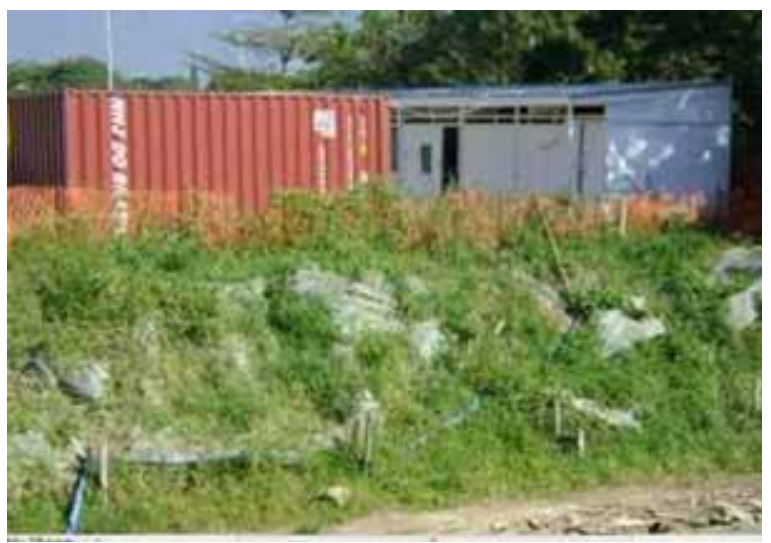

Figure 2: Embankments protected by vegetation.
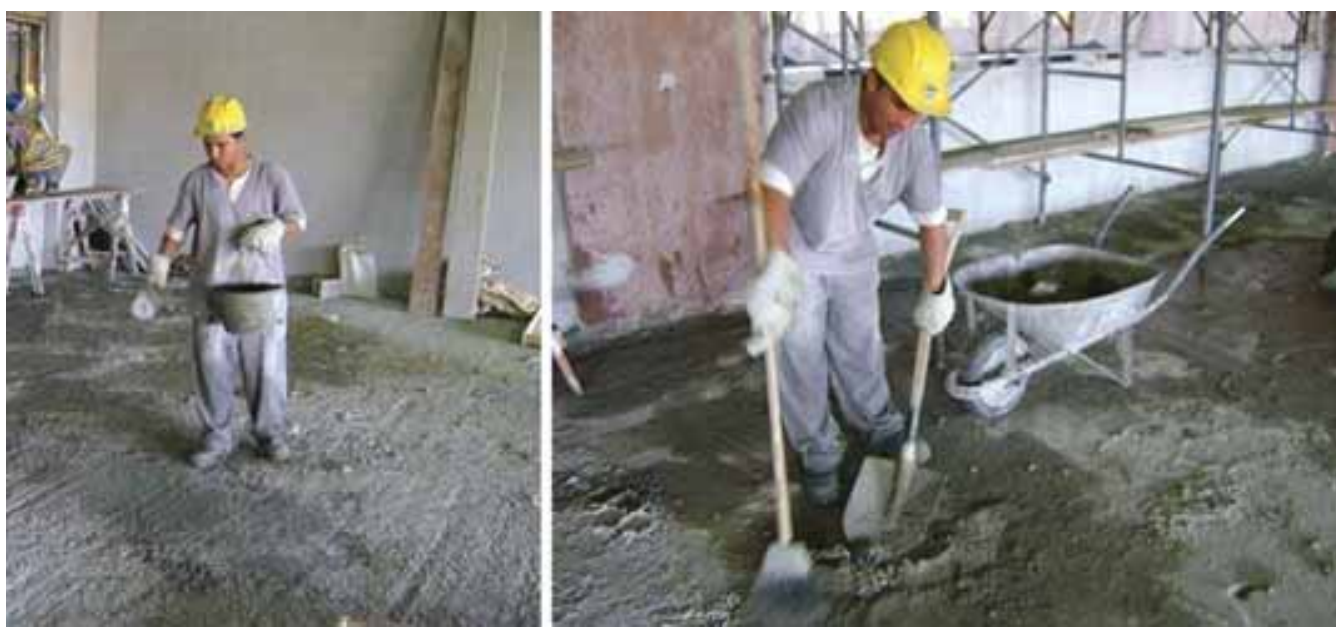

Figure 3: Sedimentation control by soaking and sweeping of the construction site.

Over time, the grass grew, was cultivated and pruned (Fig. 2), but the roots were kept intact to promote greater firmness to the soil, thereby helping the reduction in the probability of erosion.

To control sedimentation, the site was regularly soaked with water from the system to lower the water table. The wet site avoided the generation of dust by the internal circulation of vehicles. The sweeping also was also done with the soaked floor, reusing rain water (to clean the external areas of the enterprise), as observed in Fig. 3 [15].

The waste trucks leaving the construction are enclosed with canvas to avoid suspension of sediment from the bucket in the external environment. Another measure to avoid littering the streets surrounding streets was the creation of a wheel wash system, as shown in Fig. 4 [15].

The wheel wash was executed in concrete. For larger wheels, such as trucks, or for days with heavy rain and, consequently mud, an auxiliary water pump is used, as seen in Fig. 5. 


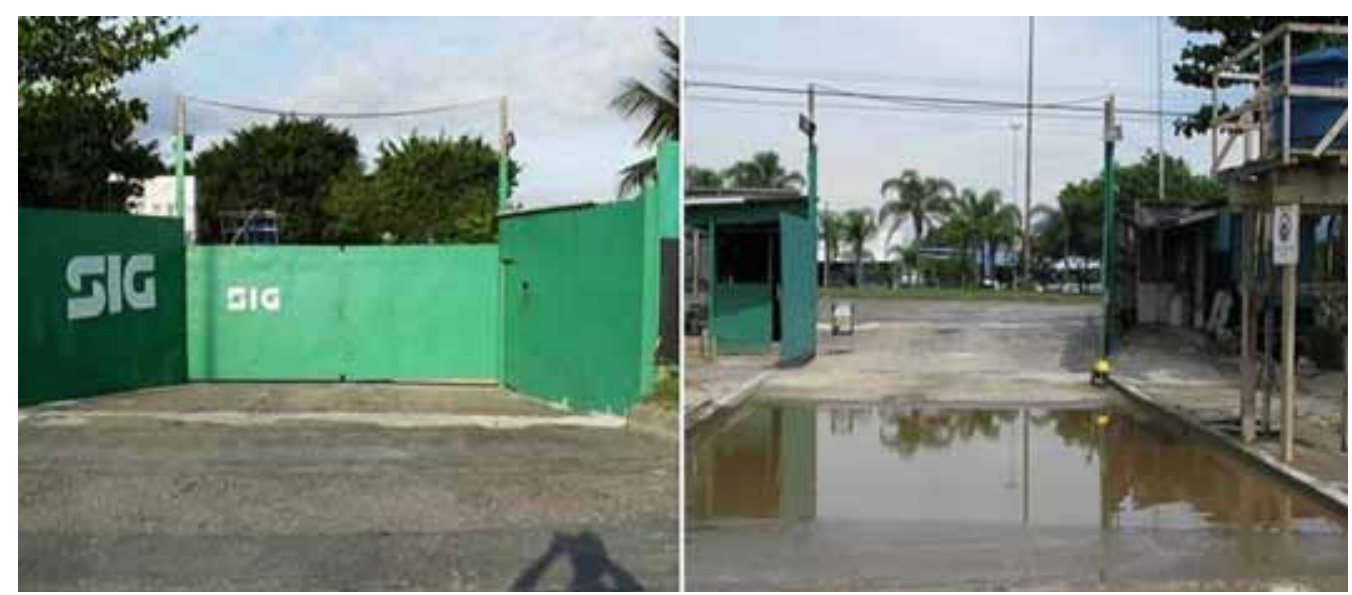

Figure 4: Site entrance and wheel wash.
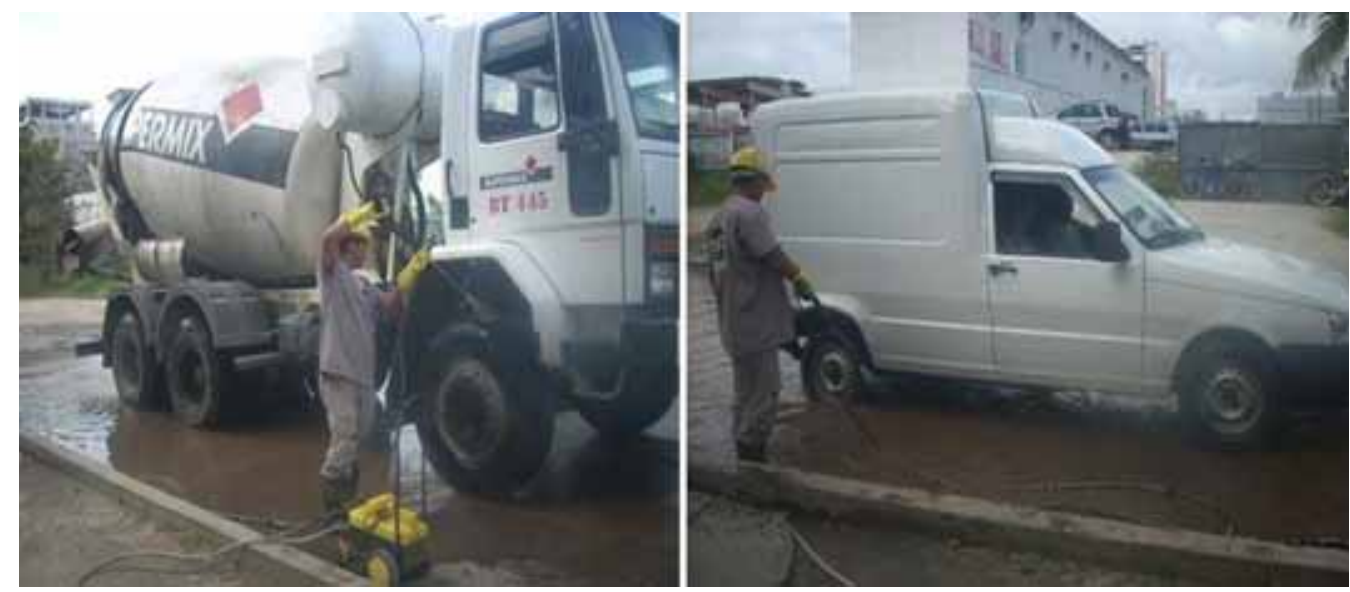

Figure 5: Auxiliary water pump.

\subsubsection{Water efficiency}

Regarding the consumption and wastage of water, Table 5 shows the impact and the intervention at the construction site.

In this category, LEED v. 2.1 does not establish any prerequisite regarding consumption of water. The points are based on the use and occupation of the enterprise, having no references to the construction site. However, to a sustainable construction site, the wastage of potable water is also considered as a critical damage to the environment.

Therefore, to reduce water consumption and avoid waste, a system to capture the water from the drawdown was adopted. This water, with a brownish tint, were used for less noble activities in the construction site, such as discharges from toilets, washing sidewalks, and cleaning of the construction site, avoiding the purchase of water trucks, or the use of the water from the dealership. To spread this concept, lectures were held regularly for the promotion of the sustainability in the construction site and the reduction of the consumption and wastage of water [15]. 
Table 5: Impacts and interventions at the construction site [15].

\begin{tabular}{lll}
\hline Water efficiency $(\mathrm{WE})$ & \multicolumn{1}{c}{ Impacts } & \multicolumn{1}{c}{ Intervention } \\
\hline & Wastage of potable water & $\begin{array}{l}\text { Reduction of the consumption of } \\
\text { potable water by reuse }\end{array}$ \\
\hline
\end{tabular}

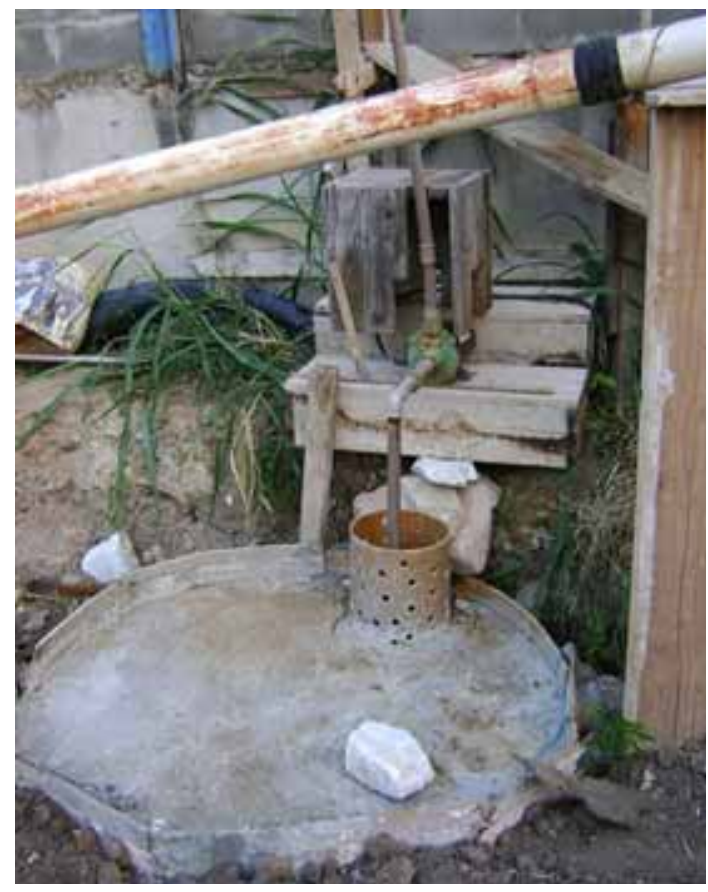

Figure 6: Capture of the water by the water table.

In the current phase of construction, the lowering of the water table has been deactivated. However, as the terrain is composed of a highly permeable soil, water percolates easily and continues to be captures for use, as shown in Fig. 6.

\subsubsection{Energy and Atmosphere}

Regarding the energy and atmosphere item, Table 6 shows the impacts and the interventions at the construction site.

The reduction of energy consumption is treated in this category, on the two prerequisites However, this item does not score the reduction performed on the construction site. But just as in the previous category, energy wastage is not permitted on a sustainable building site.

Thus, the shed was designed with many windows in order to absorb as much natural lighting and ventilation, as shown in Fig. 7. A ventilation area between the lining and ceiling tile can be observed, which decreases the absorption of heat through the roof. The electrical project contemplated independent circuit wiring, ensuring that environments are not left with lights on while idle. Compact fluorescent lamps were used in all internal areas of offices and rooms of the site. There were lectures, educational campaigns, and dissemination of this concept held to all employees. 
Table 6: Impacts and interventions at the construction site [15].

\begin{tabular}{lcc}
\hline Energy and atmosphere (EA) & Impacts & Intervention \\
\hline & Wastage of energy & $\begin{array}{l}\text { Reduction on the consumption of } \\
\text { energy with wider environments }\end{array}$ \\
\hline
\end{tabular}
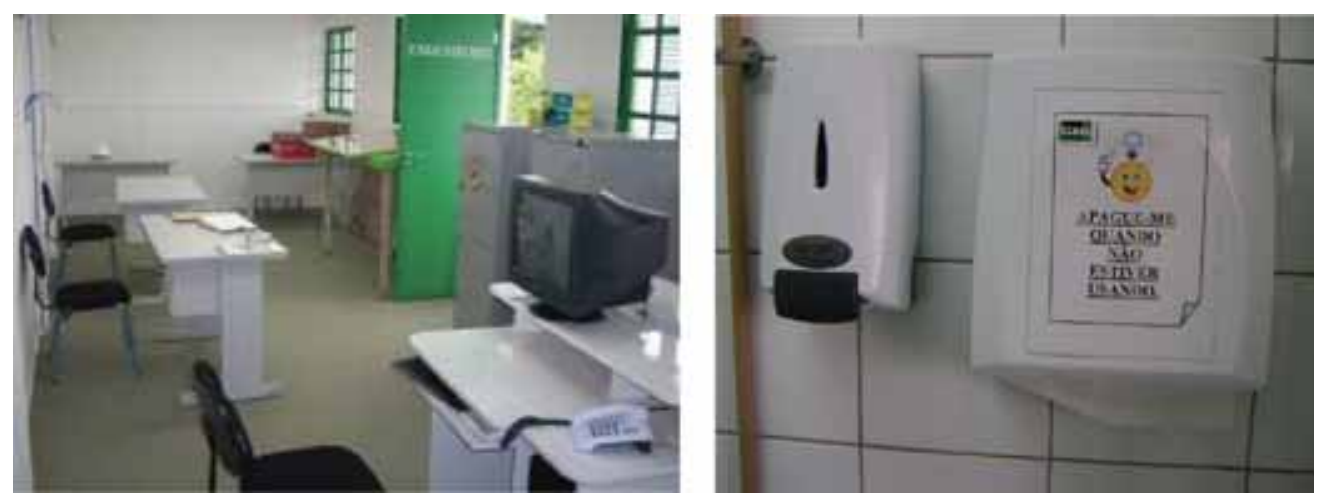

Figure 7: Technicians room, on the work shed and disclosure to reduce consumption.

\subsubsection{Material consumption and waste generation}

Regarding material consumption and waste generation, Table 7 presents the impacts and the interventions at the construction site.

This category includes the purchase of materials and the generation and management of waste. The storage and collection of recyclable waste is the only prerequisite. This item is not applied to the construction site, but is discussed on credit 2 , which refers to the construction waste management. The waste generated in the construction site is grouped separately according to the characteristics, and then sold for recycling. This measure plans to stimulate the economy by selling a product that will no longer be used and increase the useful life of landfills. There was also training conduction about the proper use of each material, in order, to avoid waste [15].

Some of the materials that were recycled, such as scrap and wood, were separated and identified in respective places on the site, and sold later to agencies and companies to recycle (Fig. 9).

From the month of July 2009 to January 2010, an average of $93.75 \%$ of waste generated on the construction site had been recycled. All material sent has a Control Waste Transport (CTR), where the sorting option for the company was noted as Recycler.

Bays for smaller waste, such as plastics and ink package, were also made, segregation was done according to the CONAMA resolution - No.307/2002. This material was grouped and sold for recycling (Fig. 10).

Organic waste, such as leftover meals, was placed in separate buckets for collection by a company specialized in the treatment of organic waste (Fig. 11).

As for the materials from the excavation, these were removed and transported to areas within the established site, and was incorporated into the landfill areas of the work itself (Fig. 12).

Materials stored on site and materials that can absorb moisture and contaminants were protected from the weather. They were placed on wood structures or on a concrete area, and covered when necessary (Fig. 13). 
Table 7: Impacts and interventions at the construction site [15].

\begin{tabular}{lll}
\hline Material and resources (MR) & \multicolumn{1}{c}{ Impacts } & \multicolumn{1}{c}{ Intervention } \\
\hline & $\begin{array}{l}\text { Solid waste generation Saturation } \\
\text { of the landfills Pollution by waste } \\
\text { and transport }\end{array}$ & $\begin{array}{l}\text { Waste management Reuse of } \\
\text { materials Use of recyclable and } \\
\text { regional materials }\end{array}$ \\
\hline
\end{tabular}
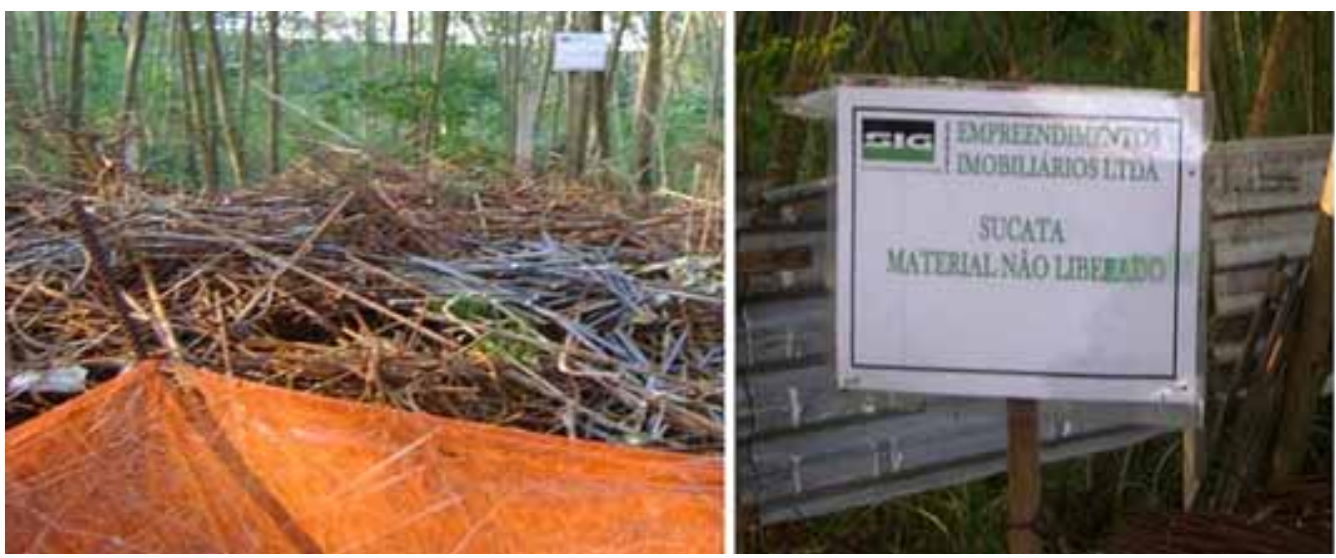

Figure 9: Scrap separated for the subsequent recycling process.

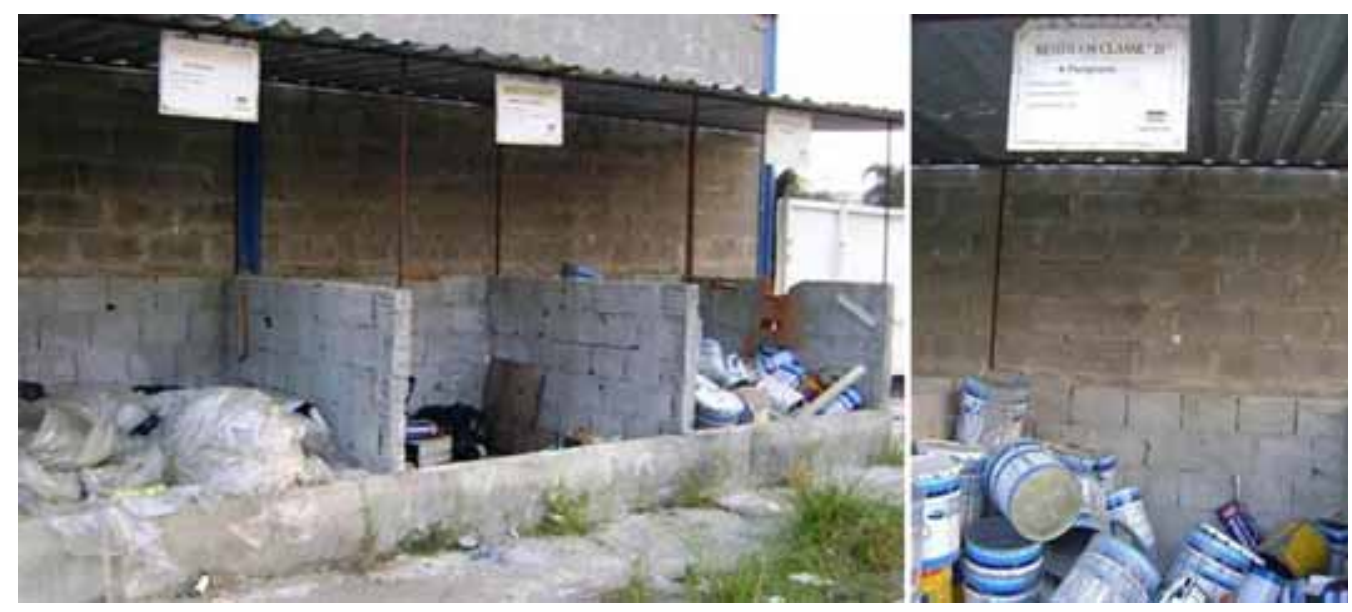

Figure 10: Separated waste on bays for recycling according to CONAMA resolution.

Other measures adopted also for the reduction of waste was the release of the traces to manufacture bedding mortar on the site at all floors and the use of plastic trough. The use reduces waste because it has a smoother surface than concrete, and has a $100 \%$ use of the produced mortar. (Fig. 14). 


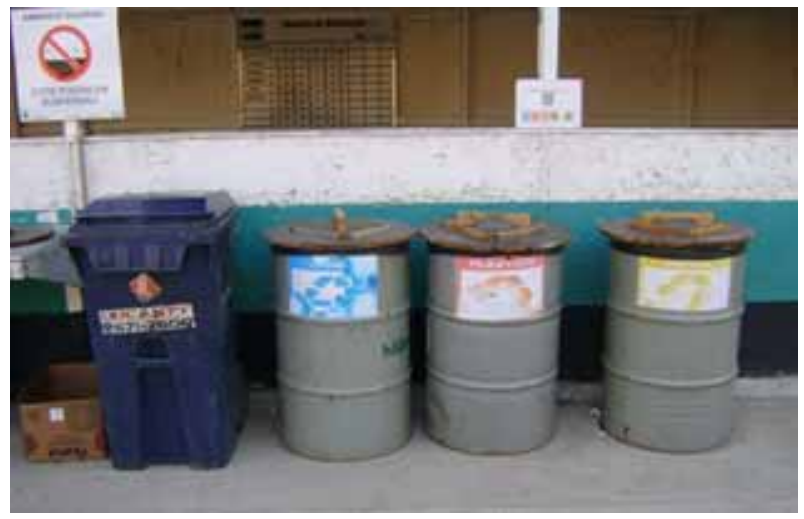

Figure 11: Separated trash cans for recycling.

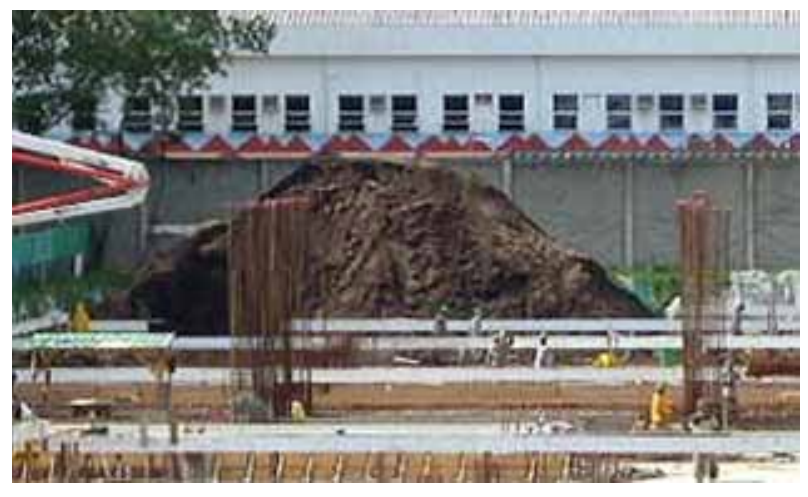

Figure 12: Excavated material that was reused for landfill.
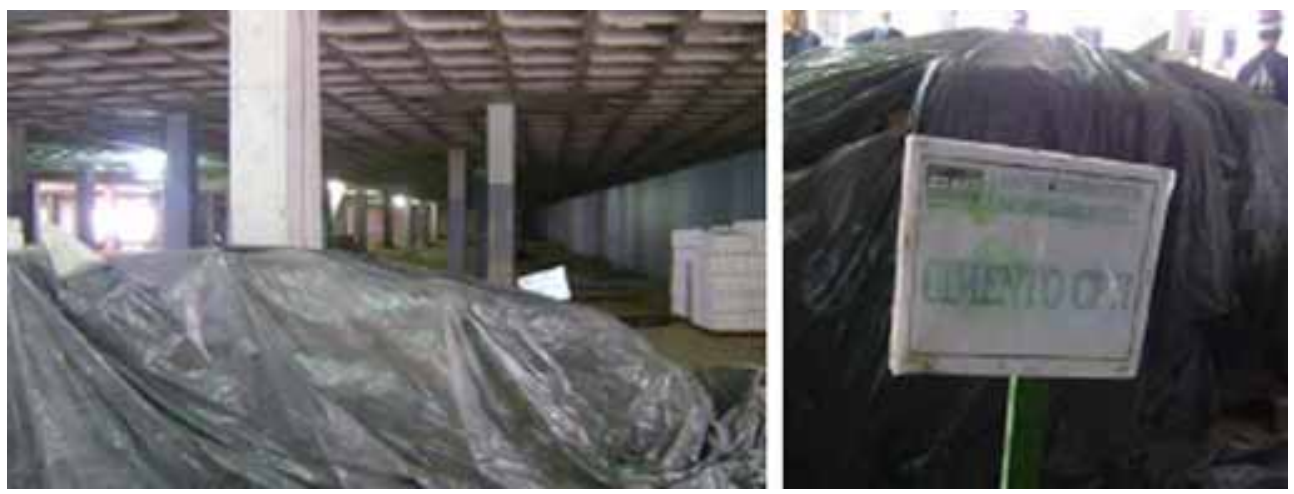

Figure 13: Storage of protected cement bags. 


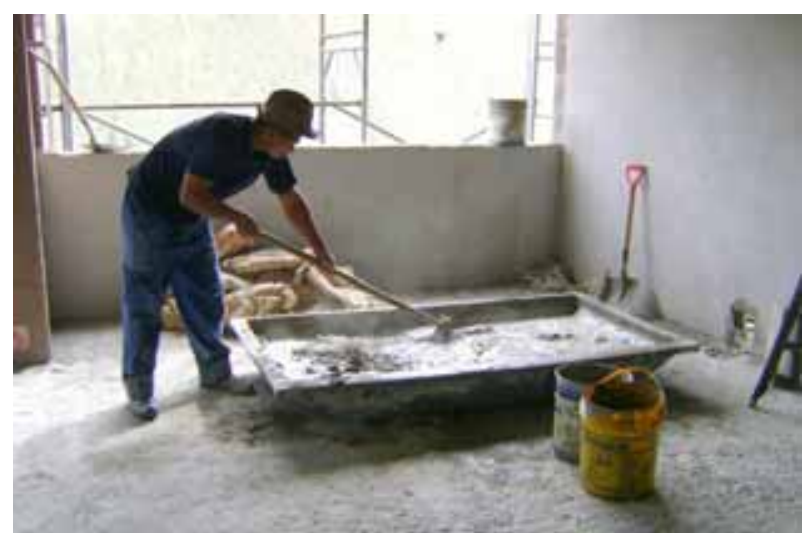

Figure 14: Use of plastic reduces waste trough.
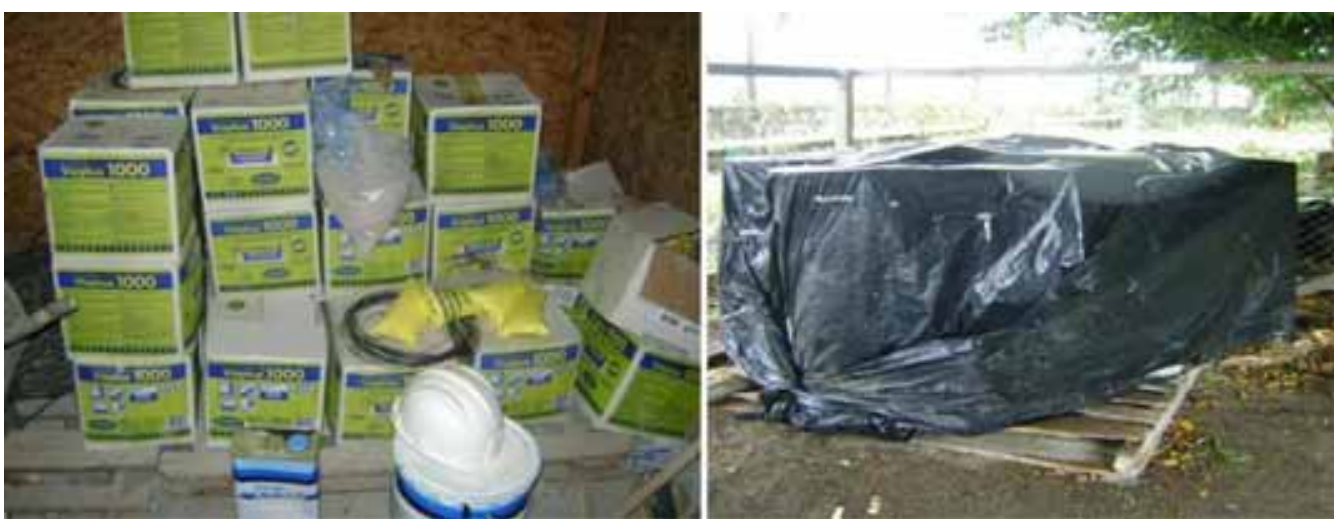

Figura 14 - Storage of waterproofing materials.

\subsubsection{Indoor environmental quality}

In this criteria, Table 8 presents the major impacts and the respective interventions.

The prerequisites in this category relate to the minimum performance of air quality and control generated by tobacco smoke. These two items are evaluated in the building already in use and is not applied to the construction site but are covered in credit 3, with regards to air quality during the construction of the building and determines the creation of a Management Plan for Air Quality. Credits 4.1, 4.2, and 4.3 relate to the use of materials with low VOC. Each item corresponds to a point in the system [15].

This plan for air quality contemplates no air pollution and material waste that can eventually release these pollutants, with some measures that are already being implemented at the construction and others that will be implemented throughout the accomplishment of the services as described below. To ensure the health of workers, smoking is not allowed to smoke inside the construction site. For that matter, a designated smoking area was created, a restricted and airy area within the plot [15].

The sequence of installation of materials was designed to avoid contamination of porous materials, such as insulation, carpeting, ceilings, and plasterboard. The surface acoustic insulation was 
Table 8: Impacts and interventions at the construction site [15].

\begin{tabular}{lll}
\hline Indoor environmental quality (EQ) & Impacts & \multicolumn{1}{c}{ Intervention } \\
\hline & Air pollution & $\begin{array}{l}\text { Reduction in carbon emissions and } \\
\text { sediment yield }\end{array}$ \\
\hline
\end{tabular}

installed only when all services that may release VOC or dust were finalized. All products that emit VOCs or odors were properly packed and stored in ventilated areas, sheltered from light (Fig. 15), and in their original containers to avoid leakage and consequent contamination of the environment. The furniture and carpet were adequately protected with plastic.

\section{FINAL CONSIDERATIONS}

With the concern regarding the preservation of the environment growing worldwide, a considerable amount of results, from conferences and debates by countries and organizations has emerged, recorded in documents, which propose some guidelines to obtain a sustainable development. These guidelines have been proposed since the 1960s, but not yet implemented by all, as was seen previously [15].

The construction industry contributes a lot towards the modification of the physical space, which can change the whole climate and produce waste and sediment that impact the environment. Therefore, the necessity arises so as to develop strategies to mitigate or cancel these impacts.

The search for sustainable construction resulted in the certification of some enterprises around the world. Besides the environmental benefits provided by sustainable construction, the certification produces a differential on the enterprise by the comfort and economy generated for the occupants and can also be used to spread and promote sales. In Brazil, the adoption of sustainable strategies is being gradually absorbed by the entrepreneurs. Some still use them aiming at the appreciation of their end product, with an objective to obtain a higher return on investment, while others use them because of a real concern for the environment. However, for whatever reasons, the growth of sustainable enterprises inspires new entrepreneurs to invest in this concept, create markets for eco-efficient products and encourage technological innovations for this purpose.

Adopting the premises for the realization of a sustainable enterprise, it is possible to meet the current needs of housing and infrastructure without compromising the ability of future generations to meet their own needs, as reported in the Brundtland Report.

As seen in this work, the construction phase of a project is responsible for much of the environmental impacts. The construction site deserves special attention and all the damage that can be generated during construction should be observed and, thus, explore ways so as to what can be avoided. In urban areas, where the highest concentration of buildings is presented, the existing ecological environment should be preserved, in order not to cause abrupt climate change, and the pollution generated should be observed, which degrades the environment and damages the neighborhood.

By the knowledge of all the impacts that may be caused by the construction site, the developer should prioritize them to determine which of these impacts should be treated and with what intensity. With this established, the technologies and the nature of managerial actions necessary can be defined, establishing the resources that must be implemented, such as equipment to be purchased, professionals to be trained or hired, management tools to be implemented, etc., and the time and cost involved.

These are the main information of interest to a professional work concerned with the issue of sustainability. These issues can be divided in some aspects to be considered. The first aspect is to 
address the costs of each building system. Costs should be observed not only for construction but also for the use and operation phases of the project. The quality and proximity to suppliers are also among the issues to be considered. It is not only important that the proper materials are selected, but also important that its use is planned to avoid losses during the construction process, with modular coordination.

There is still a great deal to be followed and learned by the construction industry regarding sustainability, but positive results in reducing environmental degradation and generating savings in the consumption of resources are driving these changes. New technologies that help these reductions can be increasingly found in the market, and with a lower differentiation of prices, resulting in lower costs for development of the enterprise. As presented in the case study, the increased costs for the hospital complex varied between 6 and 14\%, with the greatest impact on the investment generated from the electrical installation and eco-efficient air conditioners.

To improve the adoption of the concepts of sustainability in the construction industry some aspects are featured, such as the improvement in the training of professionals such as engineers and technicians, with the inclusion of disciplines that address this subject in educational institutions, the methodology employed in the construction site during the construction phase, aiming to provide a better environment for workers, for the neighborhood, and the environment and planning strategies to be implemented during construction, because it is necessary that the field staff requests eco-efficient products before the hiring of the services, among others.

\section{REFERENCES}

[1] Ubinas, Edwin Rodriguez. Arquitectura Tropical: Estrategias Bioclimaticas, Text of speech given to the Civil Engineering class - Escola Politecnica, UFRJ: Rio de Janeiro, 2009. Not published.

[2] Unesco, Mesa Verde National Park. Virtual Book, 2010. Available on: <http://www.unescoworldheritagesites.com/mesa-verde-national-park.htm>. Access on: Abril, 2010.

[3] F. Gomez \& P. Salvado. A Proposal for Green Planning in Cities. International Journal of Sustainable Development and Planning,1(1), 91-109, 2006. doi: http://dx.doi.org/10.2495/ SDP-V1-N1-91-109

[4] United Nations, Inform on the population, Department of Social and Economic Matters, Secretariat of the United Nations, 2002.

[5] Gospodini, A. Urban space morphology and place-identity in European cities; built heritage and innovative design. Journal of Urban Design, 9(2), pp. 225-248, 2004. doi: http://dx.doi. org/10.1080/1357480042000227834

[6] D'amato, Claudio. TORRES, Joao. P.M., MALM. Olaf. “DDT (Dicloro Difenil Tricloroetano) Toxidade e Contaminacao”. Quimica Nova On-Line, vol. 25, n 6a. Rio de Janeiro, 2002.

[7] Godoy, Amalia. A Conferencia de Estocolmo - Evolucao historica 2. Virtual Book, 2007. Available on: <http://amaliagodoy.blogspot.com/2007/09/desenvolvimentosustentvelevoluo_16.html>. Access on: May, 2010.

[8] Godoy, Amalia. Relatorio de Brundtland. Virtual Book, 2008. Available on: <http://amaliagodoy.blogspot.com/2008/08/relatrio-brundtland.html>. Access on: May, 2010.

[9] Ana - Agencia Nacional de Aguas. "Entenda a Rio+10". Virtual Book, 2010. Available on: $<$ http://www.ana.gov.br/AcoesAdministrativas/RelatorioGestao/Rio10/Riomaisdez/index. php.40.html . Access on: May, 2010

[10] Greenpeace, "Uniao Europeia decide ratificar protocolo de Kyoto". Virtual News, mar. 2002. Available on: <http://www.greenpeace.org/brasil/pt/Noticias/uni-oeuropeia- decide-ratifica/>. Access on: July, 2010. 
[11] Credidio, Fernando. "Construcoes sustentaveis: conforto e respeito ao meio ambiente - Parte 1". Virtual Book, 2008. http://www.ifk.org.br/construcoes_s ustentaveis:_conforto_e_respeito_ ao_meio_ambiente_parte_1_344.html.

[12] Sattler, Miguel. "Sustentabilidade: a construcao fazendo a sua parte". Conselho em Revista Materias, 33. Rio Grande do Sul, 2007.

[13] Ceotto, Luiz Henrique. "Guia de Sustentabilidade na Construcao", Minascon. Belo Horizonte, 2008.

[14] Leed, “Leadership in Energy \& Environmental Design - LEED” ,3. USGBC, 2009.

[15] E. Vazquez, S. Rola, D. Martins, M. Freitas \& L. Pinguelli Rosa. Sustainability in civil construction applied in the construction site phase. Ecosystems and sustainable development, VIII, pp. 253-264, 2011.

[16] Lima, Rosimeire Suzuki. LIMA, Ruy Reynaldo Rosa. Guia para Elaboracao de Projeto de Gerenciamento de Residuos da Construcao Civil. Serie de Publicacoes tematicas do CREA-PR, n 1. Parana, 2009. 